\title{
SISTEM KENDALI KERAN WUDHU OTOMATIS MENGGUNAKAN SENSOR PASSIVE INFRA RED (PIR) BERBASIS MIKROKONTROLER ATMEGA8535 UNTUK MENGHEMAT PENGGUNAAN AIR
}

\author{
Muhammad Hidayatullah¹, Laili Mardiana' ${ }^{1}$, Wahyudi² \\ ${ }^{1}$ Program Studi Fisika Fakultas Matematika dan Ilmu Pengetahuan Alam, Universitas Mataram, NTB \\ 2Jurusan Pendidikan Fisika Fakultas Keguruan dan Ilmu Pendidikan, Universitas Mataram, NTB
}

\begin{abstract}
ABSTRAK
Kran wudhu pada masjid maupun tempat-tempat umum saat ini masih digerakkan secara manual. Mereka masih menggunakan kran manual untuk membuka dan menutup aliran air. Kran manual mudah rusak jika sering diputar-putar, apalagi jika penggunanya kurang bijak. Kelalaian menutup kran akan mengakibatkan pemborosan air, sehingga dinilai kurang efektif dan kurang efisien. Tujuan dari penelitian ini adalah merancang sistem relai dan keran wudhu otomatis untuk memudahkan dalam berwudhu secara otomatis dan praktis. Sehingga dapat menghemat air dan listrik serta tidak perlu khawatir jika lalai menutup keran. Metode yang digunakan dalam penelitian ini yaitu metode ekperimen, yang dimulai dari perancangan sistem, pembuatan program, pengujian alat keseluruhan, pengambilan data dan pembahasan. Prinsip kerja dari sistem secara keseluruhan yaitu: pendeteksian adanya obyek tangan/kaki manusia oleh sensor infra merah. Ketika cahaya infra merah ke phototransistor terhalang oleh tangan atau kaki manusia, sinyal yang diterima tersebut akan diolah sebagai data didalam mikrokontroler, kemudian arus dari catu daya akan diteruskan untuk mengaktifkan driver relai. Jika driver relai aktif, maka tegangan 220 volt akan mengalir ke kumparan sehingga solenoid valve aktif dan air dapat mengalir keluar dari kran. Ketika sensor tidak terhalang lagi, maka solenoid valve akan off secara otomatis.
\end{abstract}

Kata kunci; Mikrokontroler, Solenoid Valve, Phototransistor, dan Relai

\section{PENDAHULUAN}

Berkembangnya teknologi yang semakin pesat dalam segala bidang/ sendi sendi kehidupan yang didukung oleh segala bentuk fasilitas terbaru yang dapat memudahkan aktivitas manusia termasuk kemudahan dalam sarana peribadatan. kita dihadapkan pada penggunaan keran wudhu secara manual. Dalam hal ini keran air akan mudah rusak karena sering diputar - putar dan terjadi pemborosan air jika lalai menutup kran. Kran yang rusak perlu penggantian secara berkala dan kelalaian menutup kran akan berakibat pemborosan air sehingga akan berakibat menambah pemakaian energi listrik. Hal inilah yang sering terjadi di masjid-masjid maupun fasilitas umum lainnya sehingga perlu dicarikan solusi penghematan air dan listrik.

Perancangan sistem merupakan modifikasi dari sistem yang sudah ada yaitu sistem kendali kran wudhu menggunakan sensor pir berbasis mikrokontroler AT89C51 tahun 2009 oleh Riza Tri Prasetyo (D-3 Teknik Elektro Universitas Negeri Malang). Sistem ini diharapkan mampu bekerja lebih baik dan simpel sehingga bisa dimanfaatkan sebagai sarana pengembangan ilmu pengetahuan dan teknologi bagi mahasiswa serta aplikasinya dapat dimanfaatkan bagi masyarakat umum.

Adapun rumusan masalah yang telah dikaji dalam penelitian ini yaitu; (a) Bagaimana merancang sistem relay secara otomatis? (b) Bagaimana merancang rangkaian aplikasi mikrokontroler untuk kran wudhu otomatis?. Penelitian ini diharapkan memberikan manfaat berupa aplikasi sensor berbasis mikrokontroler untuk pengoperasian keran wudhu sehingga dapat dimanfaatkan oleh masyarakat luas. Selain itu efisiensi penggunaan air dan listrik untuk kebutuhan wudhu pada masjid-masjid serta sebagai acuan bagi 
mahasiswa yang ingin melanjutkan penelitian dengan aplikasi lain.

\section{METODE PENELITIAN}

\subsection{Alat dan Bahan}

Adapun alat dan bahan yang digunakan dalam perancangan sistem kendali keran wudhu otomatis ini yaitu; Mikrokontroler ATMega 8535L, Keran solenoid (solenoid valve), IC ULN2003, Resistor (4K7, $240 \mathrm{~K}$, $10 \mathrm{~K}, 100 \mathrm{~K}, 2 \mathrm{~K} 7,220 \mathrm{~K}$ ), Fototransistor, Diode IN4002, LED merah, LED Infra Red
(IR), Kristal $12 \mathrm{MHz}$, Soket IC (14, 16, dan 40 kaki), Pin konektor, Papan PCB bolong, Relay 6 Volt (5 kaki), Downloader ATMega8535, Solder, Penyedot timah dan timah.

\subsection{Diagram Blok Sistem}

Perancangan aplikasi mikrokontroler untuk otomatisasi kran wudhu ini termasuk dalam sistem kendali terbuka (open loop system) yang terdiri dari beberapa blok, meliputi:

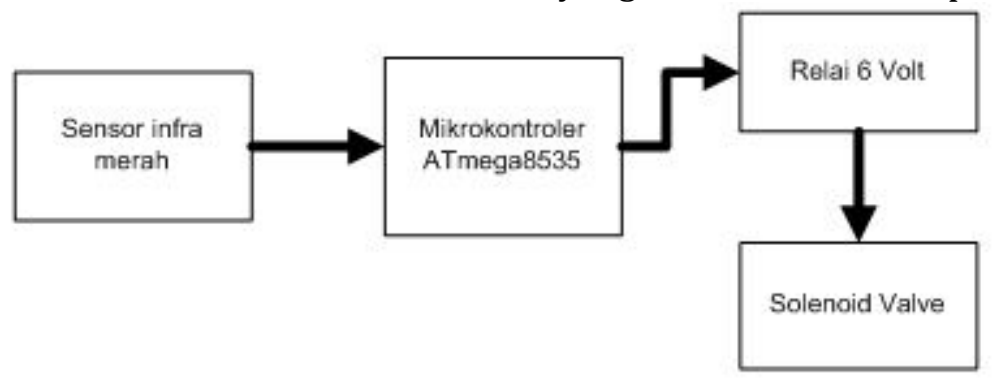

\section{Gambar 1. Diagram Blok Sistem}

Sensor Infra merah yang terdiri dari LED IR (LED Infra Red) berfungsi sebagai pemancar sinar infra merah dan phototransistor berfungsi sebagai penerima sinar infra merah/mendeteksi adanya obyek, dalam hal ini adalah tangan maupun kaki orang yang berwudhu. Mikrokontroler ATMega 8535 berfungsi sebagai pengendali utama atau pengontrol seluruh sistem (Ardianto, 2008). Driver relai digunakan untuk menjembatani pengaktifan solenoid valve. Solenoid valve digunakan sebagai buka-tutup keluarnya air.

\subsection{Perancangan Hardware}

Perancangan Minimum Sistem

Perancangan rangkaian minimum sistem ini yaitu rangkaian minimum sistem dengan komponen utama adalah mikrokontroler ATMega 8535 dan beberapa komponen tambahan, yaitu 1 buah kristal $12 \mathrm{MHz}$, 2 buah kapasitor keramik $30 \mathrm{pF}, 1$ elco 10 $\mathrm{uF}$ dan resistor $10 \mathrm{~K} \Omega$. Program yang digunakan yaitu CodeVision AVR yang khusus digunakan untuk mikrokontroler keluarga ATMEL.

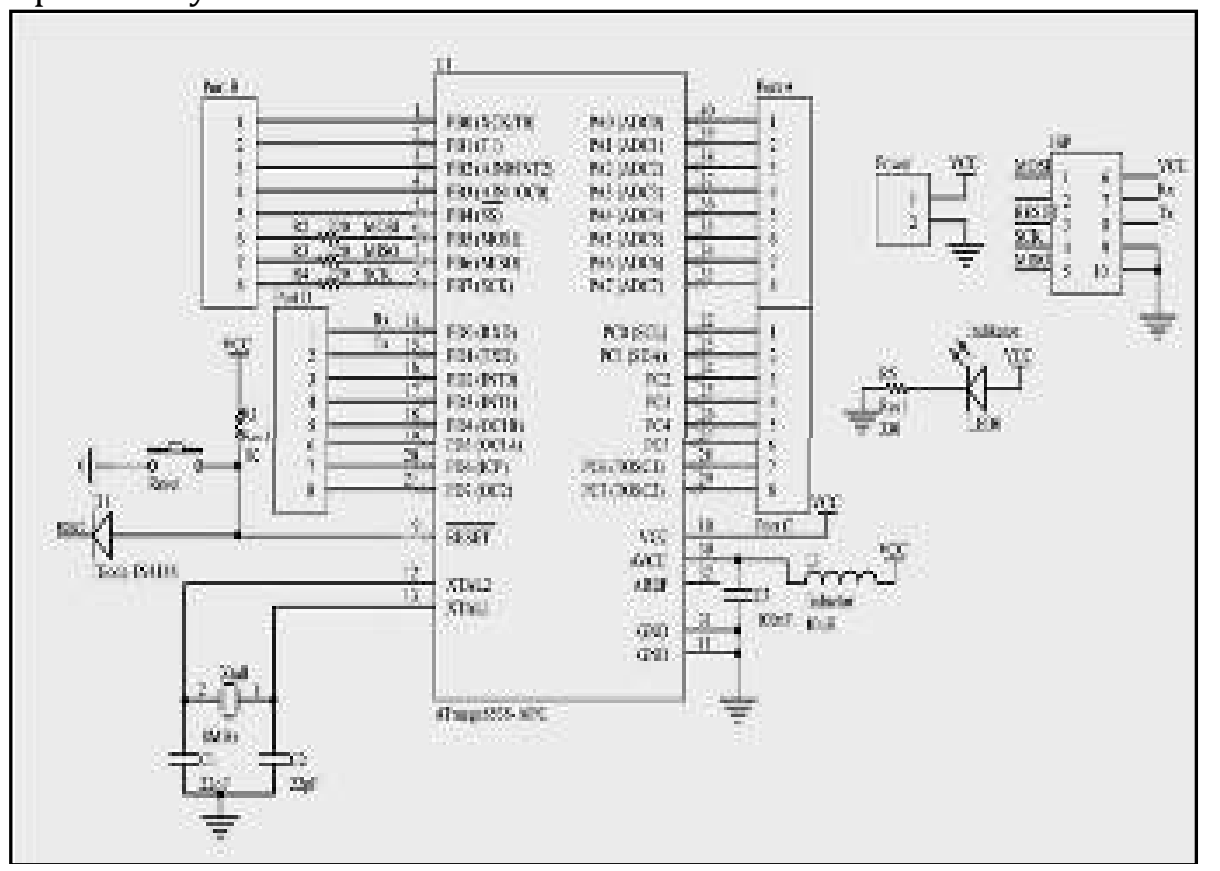

Gambar 2. Rangkaian Minimum Sistem ATmega8535 (Budiharto, 2005) 
Kemudian dibuat rangkain sensor pendeteksi adanya obyek menggunakan phototransistor. Dipilih phototransistor karena mempunyai sensitifitas yang lebih tinggi dari pada photodioda. LED IR harus dipasang forward bias dan untuk menyesuaikan arus yang boleh melewati komponen menurut data sheet, maka sebelum tegangan yang masuk ke LED IR harus diberi resistor. Pemasangan phototransistor dihubungkan seri dengan sebuah tahanan $\mathrm{R}$ dan dicatu dengan sumber tegangan DC. Resistor berfungsi sebagai tahanan bagi phototransistor sehingga tidak mudah rusak akibat adanya perubahan tegangan atau arus yang masuk. Agar memudahkan perancangan maka dipakai resistor $4 \mathrm{~K} 7 \Omega$. Berikut disajikan gambar rangkain sensor pendeteksi adanya obyek menggunakan phototransistor.

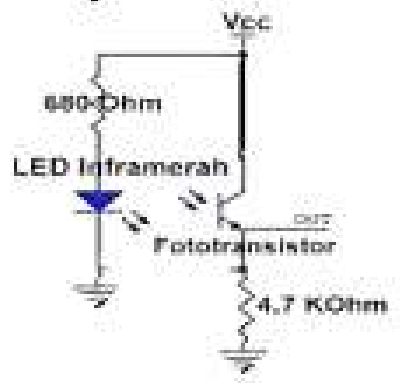

Gambar 3. Rangkaian Sensor Infra Red dengan Phototransistor (Sugiarto, 2002)

Kemudian dibuat rangkaian driver solenoid valve yang difungsikan sebagai saklar. Untuk itu digunakan relai sebagai saklar elektronik otomatis untuk mengaktifkan solenoid valve. Rangkaian ini disajikan dalam gambar 4 berikut.

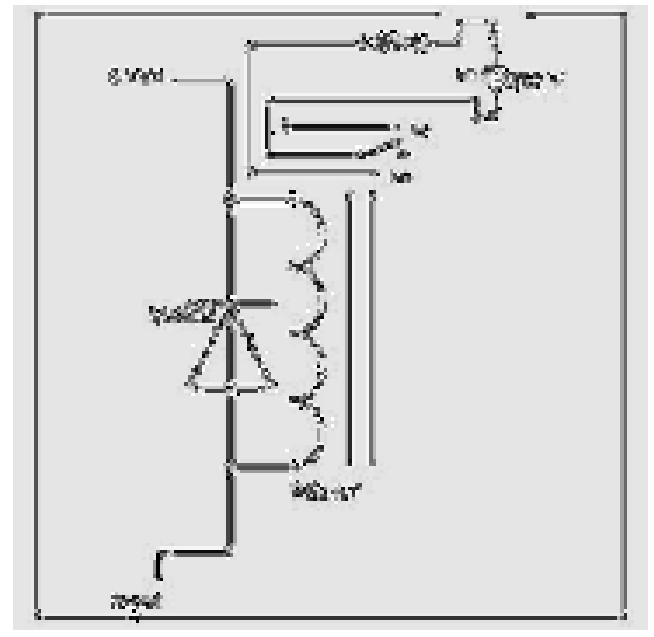

\section{Gambar 4. Rangkaian Driver Relai (Sutrisno, 2009)}

Rangkaian-rangkaian ini mendapatkan supplay tegangan dari rangkaian catu daya. Rangkaian catu daya memberikan supply tegangan pada alat pengendali. Rangkaian catu daya mendapatkan sumber tegangan dari listrik PLN sebesar 220 VAC.

\subsection{Perancangan Software}

Perancangan software pada sistem otomatisasi kran wudhu ini dilakukan untuk memproses input dengan manipulasi output. Software yang dipakai menggunakan bahasa $\mathrm{C}$ yang diolah dengan menggunakan program AVR (Chandra, 2010). Inisialisasi data yang dilakukan pada program yaitu pengaturan port-port mikrokontroler ATMega 8535 yaitu port A, port B, port $C$ atau port D. Untuk pemrograman software, mengikuti flowchart kerja yang sudah dirancang sebelumnya. Berikut disajikan flowchart kerja dari penelitian ini

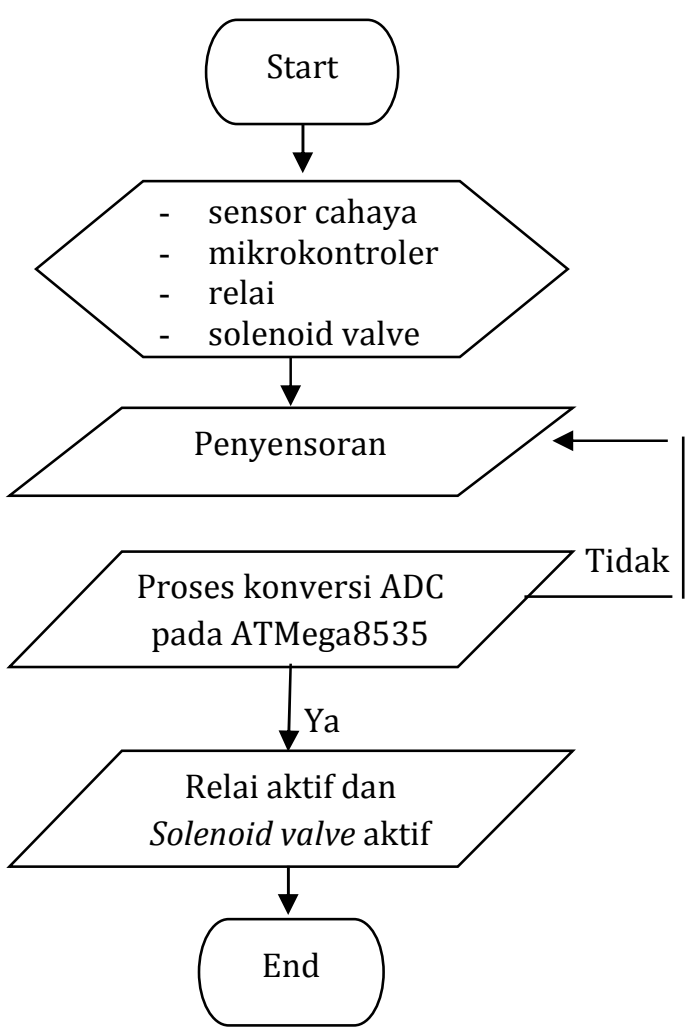

Gambar 5. Flowchart Kerja Sistem 
Untuk memulai kerja alat, mikrokontroler akan melakukan pembacaan port, yaitu merespon sinyal dari sensor. Apabila terdeteksi adanya obyek pada sensor, maka mikrokontroler akan memberikan logika low pada port yang artinya solenoid valve aktif dan ketika sensor tidak mendeteksi obyek lagi, maka kran air akan menutup. Selama program berlangsung, mikrokontroler terus-menerus melakukan pembacaan port mana yang aktif. Akan tetapi bila tombol reset ditekan, maka sistem akan mereset ulang kerja dari sistem secara keseluruhan.

\section{HASIL DAN PEMBAHASAN}

Hasil pengujian dari rangkaian sensor pendeteksi adanya obyek (LED IR dan phototransistor) digunakan untuk menganalisis tegangan rangkaian saat diberi penghalang tangan dan tidak diberi penghalang. Pengujian rangkaian sensor dilakukan dengan menggunakan multimeter untuk mengetahui tegangan keluaran yang dihasil-
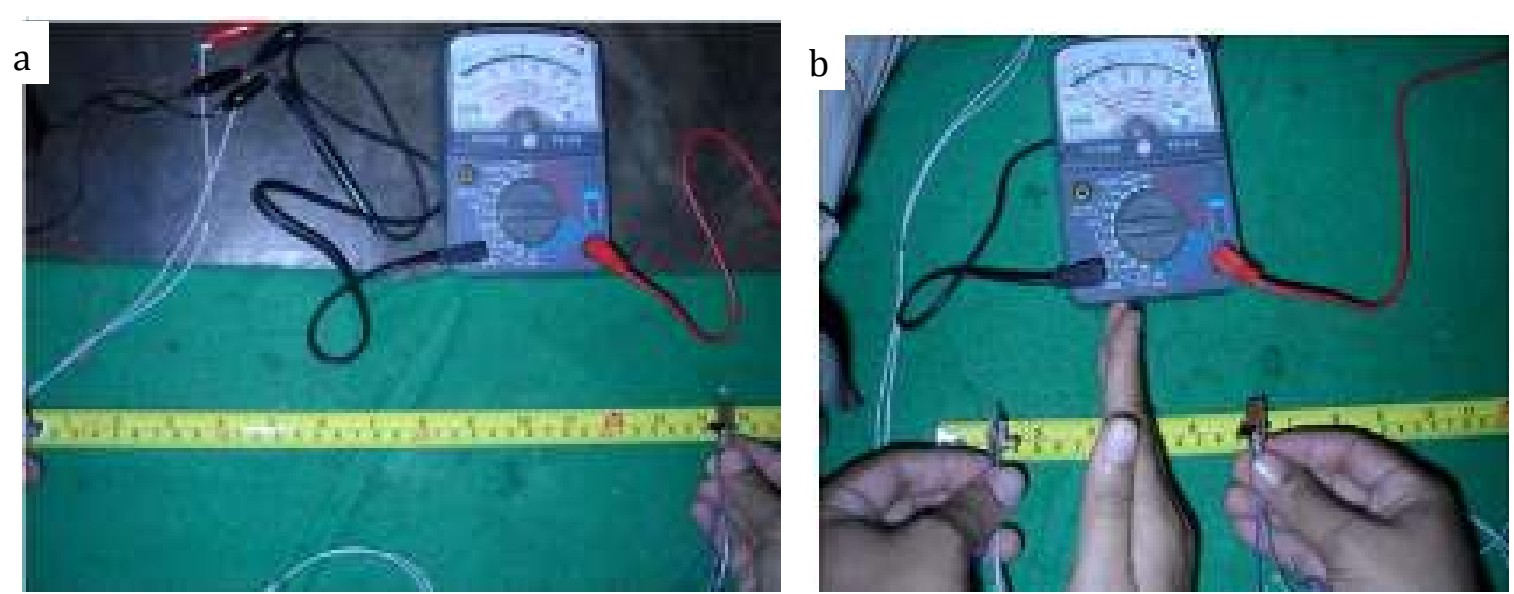

Gambar 6a. Rangkaian Sensor Pendeteksi Adanya Obyek Saat Tidak Terhalang

Gambar 6b. Rangkaian Sensor Pendeteksi Adanya Obyek Saat Diberi Penghalang

Tabel 1. Hasil pengukuran sensor pendeteksi obyek saat tidak terhalang.

\begin{tabular}{|c|c|c|}
\hline Pengukuran & Jarak $(\mathrm{cm})$ & Tegangan (volt) \\
\hline 1 & 4 & 5.0 \\
\hline 2 & 8 & 5.0 \\
\hline 3 & 12 & 5.0 \\
\hline 4 & 16 & 5.0 \\
\hline 5 & 20 & 5.0 \\
\hline 6 & 24 & 5.0 \\
\hline 7 & 28 & 5.0 \\
\hline 8 & 32 & 5.0 \\
\hline 9 & 36 & 5,0 \\
\hline 10 & 40 & 4,6 \\
\hline
\end{tabular}

kan oleh sensor pada jarak yang berbeda, dimana katoda LED IR terhubung ke ground catu daya, sedangkan anodanya dihubungkan ke katoda fototransistor yang juga terhubung ke Vcc 5 volt. Sementara anoda dari fototransistor berfungsi sebagai keluaran (output) sensor. Pengukuran ini dilakukan sebanyak 15 kali untuk masingmasing keadaan dari jarak $4 \mathrm{~cm}$ sampai 60 $\mathrm{cm}$ menggunakan range skala 4. Saat dilakukan pengujian pertama tanpa terhalang, tegangan yang dihasilkan sebesar 5 volt. Hasil pengujian memiliki tegangan yang konstan yaitu 5 volt hingga jarak $36 \mathrm{~cm}$. Artinya rangkaian sensor ini dapat bekerja dengan sangat baik hingga jarak $36 \mathrm{~cm}$.

Sedangkan untuk pengujian kedua, ketika sensor diberi penghalang, tegangan yang dihasilkan dari jarak $4 \mathrm{~cm}$ sampai 60 cm tetap 0 volt. Karena tidak ada cahaya infra merah yang ditangkap oleh phototransistor, sehingga tegangannya tetap. Dari hasil pengujian ini dapat disimpulkan sensor sudah bisa bekerja dengan sangat baik. 


\begin{tabular}{|l|l|l|}
\hline 11 & 44 & 4,5 \\
\hline 12 & 48 & 4,2 \\
\hline 13 & 52 & 3,8 \\
\hline 14 & 56 & 3,4 \\
\hline 15 & 60 & 3,0 \\
\hline
\end{tabular}

Tabel 2. Hasil pengukuran sensor pendeteksi obyek saat diberi penghalang

\begin{tabular}{|c|c|c|}
\hline Pengukuran & Jarak $(\mathrm{cm})$ & Tegangan (volt) \\
\hline 1 & 4 & 0 \\
\hline 2 & 8 & 0 \\
\hline 3 & 12 & 0 \\
\hline 4 & 16 & 0 \\
\hline 5 & 20 & 0 \\
\hline 6 & 24 & 0 \\
\hline 7 & 28 & 0 \\
\hline 8 & 32 & 0 \\
\hline 9 & 36 & 0 \\
\hline 10 & 40 & 0 \\
\hline 11 & 44 & 0 \\
\hline 12 & 48 & 0 \\
\hline 13 & 52 & 0 \\
\hline 14 & 56 & 0 \\
\hline 15 & 60 & 0 \\
\hline
\end{tabular}

\section{Pengujian Relay}

Pada pengujian relay ini, yaitu dengan cara memberikan tegangan DC 5 Volt pada kumparannya dan mengamati perubahan pada kontak-kontaknya. Untuk mengamati kontaknya, yaitu dengan menggunkan Ohmmeter analog untuk mengetahui putus tidaknya kontak. Rangkaian driver relai diuji dengan catu daya untuk mngetahui aktif atau tidak, relai 6 volt dirangkai dengan dioda IN4002 dan dihubungkan ke tegangan 5 volt.

Dioda ini berfungsi sebagai pengarah arus yang masuk ke relai dan mencegah arus balik dari relai. Saat terhubung, relai mendengung sebagai tanda aktif dan menandakan arus yang tersambung dari catu daya dengan relai sudah pas. Dari hasil pengujian diatas, perubahan kondisi kontak pada relay dari NO menjadi NC ataupun sebaliknya merupakan fungsi relai, sehingga relay dapat berfungsi dengan baik.

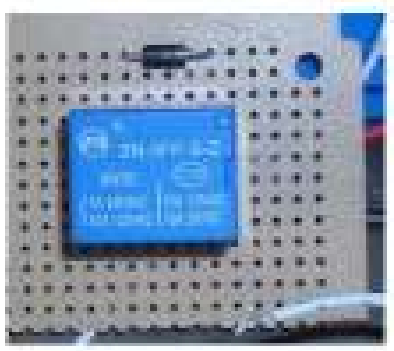

Gambar 7. Rangkaian relay

Tabel 3. Pengujian relai

\begin{tabular}{|c|c|}
\hline Kondisi kontak sebelum koil relai dicatu & Kondisi kontak setelah koil relai dicatu \\
\hline NO & NC \\
\hline NC & NO \\
\hline
\end{tabular}

\section{Pengujian Solenoid Valve}

Untuk memastikan solenoid valve ini berfungsi dengan baik, Solenoid val$v e$ diberikan tegangan 220 Volt (AC) dan mengeluarkan bunyi mendengung pada kumparannya, kemudian dilakukan peniupan angin pada bagian masukkanya dan keluarlah angin pada ujung pangkal kran. Ketika kumparannya tidak diberi tegangan, maka angin 
yang ditiupkan tidak keluar. Saat solenoid valve diuji dengan driver relai, solenoid valve diberi tegangan 220 Volt, dan driver tersambung ke tegangan 5 volt, ketika relai disambungkan ke solenoid valve, saat itu juga relai dan solenoid valve aktif secara bersamaan. Dari hasil pengujian, rangkaian driver solenoid valve dapat bekerja dengan baik.

Hasil pengujian minimum sistem adalah dilakukan dengan menggunakan program $C V$-AVR yang di-download ke mikrokontroler. Fitur dari codewizard yang diseting yaitu;

- Chip yang digunakan yaitu ATmega8535L

- Clocknya dirubah menjadi 11,059000 MHz. Port yang dirubah yaitu Port C, Bit-nya di klik menjadi out semua.

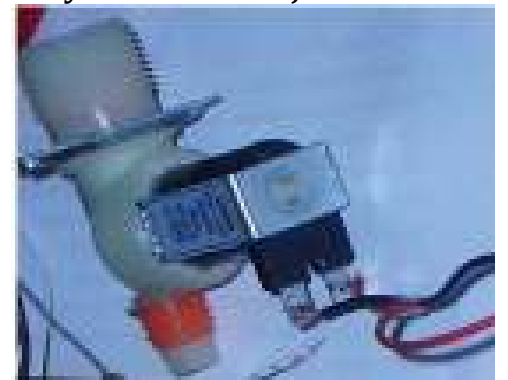

Gambar 9. Solenoid valve

\section{Pengujian Rangkaian Keseluruhan}

Listing program keseluruhannya adalah;

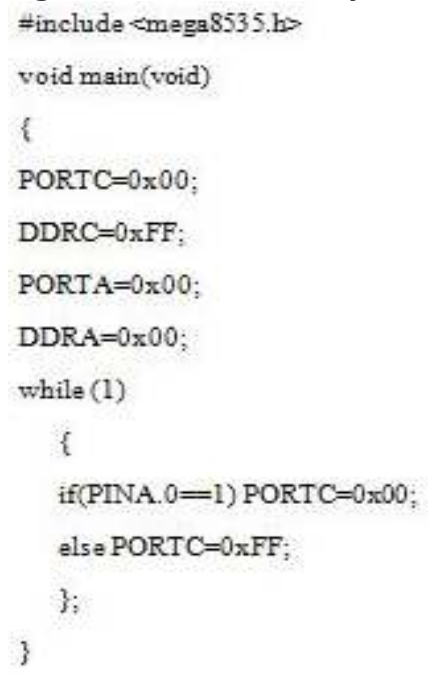

\section{Gambar 10. Listing Program}

\section{Keseluruhan}

Untuk mengetahui outputnya digunakan rangkaian LED sebagai indikator. Setelah dilakukan pengujian, LED indikator akan menyala jika sensor pendeteksi objek terhalang oleh tangan dan akan mati jika sensornya tidak terhalangi sesuai dengan program yang dibuat. Dari hasil tersebut dapat dianalisis bahwa minimum sistem mikrokontroler ATMega8535 dapat berfungsi dengan baik.

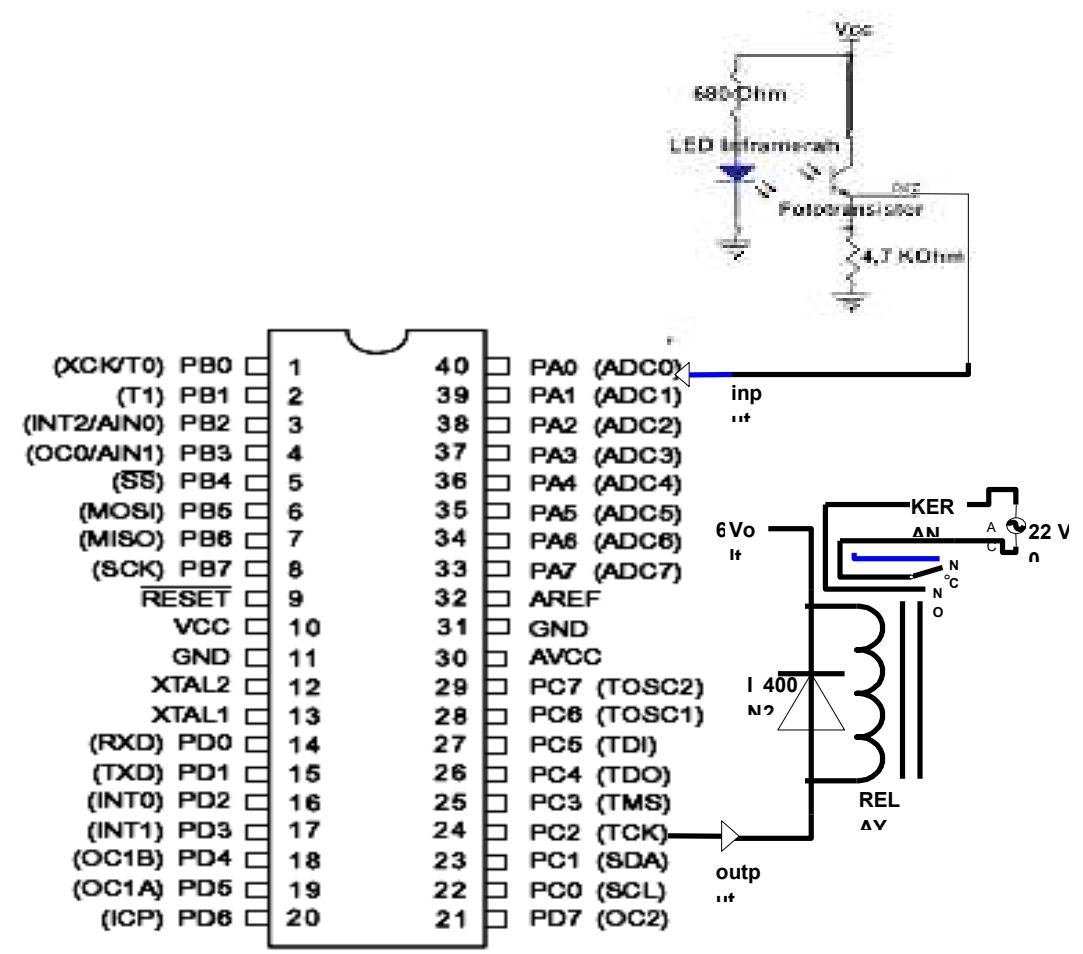




\section{Gambar 11. Diagram Sistem Keseluruhan}

Pada saat ada obyek yang menghalangi sinar infra merah ke fototransistor, sinyal tersebut masuk ke mikrokontroler melalui port PortA.0 yang kemudian dibaca oleh mikrokontroler sebagai data untuk direspon berdasarkan instruksi yang telah di inputkan. Kemudian mikrokontroler akan memberikan respon pada PortC untuk mengaktifkan relai dan pada saat bersamaan solenoid valve akan aktif sehingga air akan keluar. Jika obyek tidak terdeteksi lagi maka secara otomatis mikrokontroler tidak akan mengatifkan Port lagi seiring dengan tidak terhalangnya lagi cahaya infra merah ke fototransistor, sehingga solenoid valve dan relainya menjadi tidak aktif yang mengakibatkan tidak ada air yang keluar dari solenoid valve tersebut. Dalam arti sistem ini akan off jika tidak ada obyek sebagai penghalang sinar infra red ke fototransistor.

Secara keseluruhan, prinsip kerja dari sistem ini dapat dijelaskan sebagai berikut; Gerakan tangan manusia diiden- tifikasi oleh sensor infra merah. Ketika cahaya infra merah ke phototransistor terhalang oleh tangan atau kaki manusia, output dari rangkaian sensor masuk ke PortA.0, kemudian mikrokontroler akan mengoperasikan data yang masuk dan mengisyaratkan pada portC untuk mengaktifkan relai, maka secara bersamaan solenoid valve aktif dan mengeluarkan air. Setelah tidak ada objek yang masuk diantara kedua sensor phototransistor dan LED IR atau sensornya tidak terhalang lagi, maka mikrokontroler akan mengisyaratkan potr C untuk off sehingga secara otomatis keran solenoid valve akan berhenti mengeluarkan air. Secara sederhana sistem ini telah mapu bekerja dengan baik untuk mengontrol keluar masuknya air dari keran untuk kebutuhan wudhu maupun kebutuhan lainnya. Dengan sistem otomatis ini maka akan diperoleh penggunaan air yang sangat hemat sesuai dengan kebutuhan saja sehingga secara tidak langsung akan menghemat penggunaan listrik PLN.

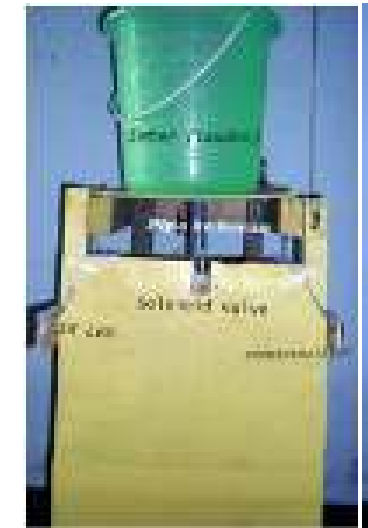

(a)Tampak depan

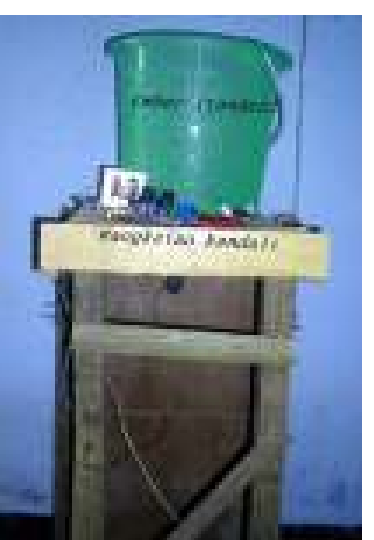

(b) Tampak belakang

Gambar 12. Hasil Rancangan Keseluruhan Sistem Kendali Keran Otomatis

\section{KESIMPULAN}

Berdasarkan hasil pengujiandan analisis prototype dari system kendali keran wudhu otomatis yang telah dibuat, maka dapat disimpulkan bahwa :

1. Prototype yang dibuat dapat bekerja dengan sangat baik, dimana ketika tangan menghalangi sensor, keran solenoid dapat mengeluarkan air, begitu juga jika tangan dilepaskan lagi maka air akan berhenti keluar dari keran secara otomatis.
2. Hasil perancangan keseluruhan, aplikasi mikrokontroler untuk otomatisasi kran wudhu dapat digunakan sebagai pengganti kran manual agar lebih efektif dan efisien dalam menghemat penggunaan air serta akan menghemat penggunaan listrik PLN.

\section{DAFTAR PUSTAKA}

Ardianto. Heri.2008. Pemprograman Mikrokontroler AVR ATMEGA 16 
Menggunakan Bahasa C (Code Vision AVR). Informatika: Bandung.

Budiharto, Widodo.2005. Elektronika Digital dan Mikroprosesor. Yogyakarta: Penerbit Andi.

Chandra Franky dan Deni Arifianto.2010. Jago Elektronika Rangkaian Sistem Otomatis. Jakarta: Kawan Pustaka.
Sugiarto, Agus.2002. Penerapan Dasar Transducer dan Sensor. Yogyakarta: Penerbit Kanisius.

Sutrisno.2009. Elektronika Lanjut, Teori Dasar dan Penerapannya. Bandung: ITB Press 